\title{
Preliminary Investigation of Sex Differences in Procedural Skill Learning in Veterans with Co-Morbidities
}

\author{
Dana Waltzman 1,2*, Michelle Madore ${ }^{3}$, Margaret W. McNerney,2, Timothy C. Durazzo1,2,4, \\ Jyoti V. Bhat ${ }^{5}$, Jerome Yesavage1,2,4, Maheen M. Adamson' ${ }^{2,6}$, Ansgar J. Furst ${ }^{1,2,7}$ \\ ${ }^{1}$ War Related Illness and Injury Study Center (WRIISC), Veterans Affairs Palo Alto Health Care System, Palo Alto, CA, USA \\ ${ }^{2}$ Department of Psychiatry and Behavioral Sciences, Stanford University School of Medicine, Palo Alto, CA, USA \\ ${ }^{3}$ Department of Psychology, Veterans Affairs Palo Alto Health Care System, Palo Alto, CA, USA \\ ${ }^{4}$ Mental Illness Research and Education Clinical Centers, Veterans Affairs Palo Alto Health Care System, Palo Alto, CA, USA \\ ${ }^{5}$ Palo Alto Veterans Institute for Research, Palo Alto, CA, USA \\ ${ }^{6}$ Defense Veterans Brain Injury Center (DVBIC), Veterans Affairs Palo Alto Health Care System, Palo Alto, CA, USA \\ ${ }^{7}$ Department of Neurology and Neurological Sciences, Stanford University School of Medicine, Palo Alto, CA, USA \\ Email: *nmc3@cdc.gov
}

How to cite this paper: Waltzman, D., Madore, M., McNerney, M.W., Durazzo, T.C., Bhat, J.V., Yesavage, J., Adamson, M.M. and Furst, A.J. (2017) Preliminary Investigation of Sex Differences in Procedural Skill Learning in Veterans with CoMorbidities. Journal of Behavioral and Brain Science, 7, 325-337.

https://doi.org/10.4236/jbbs.2017.78024

Received: June 14, 2017

Accepted: July 29, 2017

Published: August 1, 2017

Copyright (c) 2017 by authors and Scientific Research Publishing Inc. This work is licensed under the Creative Commons Attribution International License (CC BY 4.0).

http://creativecommons.org/licenses/by/4.0/

\section{(c) (i) Open Access}

\begin{abstract}
Sex differences in procedural skill learning have not been well characterized. Skill learning is an important area to explore in clinical settings that involve rehabilitation and deficit remediation, especially for returning Veterans that have a range of co-morbid conditions (traumatic brain injury, posttraumatic stress disorder, and depression) and possess impairments in multiple domains. Sixty-five (55 males, 10 females) Veterans completed two procedural learning tasks and answered self-report questionnaires. Participants' performance and total learning slope were analyzed to determine sex differences in learning. Our results revealed sex differences in both tasks demonstrating females tend to perform better than males with a large effect size for these mean differences. While females performed better on the procedural learning tasks compared to males, their rate of learning was equivalent. Skill learning is an important requisite for rehabilitation, as skill learning is necessary to perform daily activities in new settings. Ultimately, these results provide insight into skill learning in Veterans with a range of co-morbid conditions and provide support for further investigation of sex differences in procedural learning.
\end{abstract}

\section{Keywords}

Sex, Memory, Procedural Learning, Veterans, Co-Morbidity 


\section{Introduction}

Veterans who have been exposed to combat are at greater risk for traumatic brain injury (TBI), posttraumatic stress disorder (PTSD), and/or depression [1] [2] [3] [4]. The prevalence of TBI in Veterans ranges from 15\% - 30\% [5] [6], $10 \%-30 \%$ for PTSD [1] [7], and 11.5\% - 16\% for depression [7]. These conditions are also related to impairments in cognition and memory [2] [8] [9] [10]. However, one domain that has not been well characterized in Veterans is procedural learning, particularly skill learning. Long-term memory can be divided into two main domains, declarative (explicit) memory and non-declarative (implicit) memory. Declarative memory is the conscious recollection of facts and events, while non-declarative memory occurs without conscious awareness and is expressed through performance [11] [12]. Procedural learning is a type of non-declarative learning that occurs gradually via repetition and often involves acquisition of motor and cognitive skills [11].

Skill learning is an important area to explore in clinical settings that involve rehabilitation and deficit remediation. For example, physical and occupational therapy are disciplines that heavily rely on procedural learning for motor skills. Though learning is acquired gradually and through practice, the skills learned in these therapies benefit from generalizability of one skill to another similar skill [13]. Similarly, cognitive rehabilitation is a behavioral intervention for various disorders that aims to restore, compensate, or optimize cognitive functions that target skills and improves daily functioning (see [14] for an example, [15] [16]).

Learning and memory are also influenced by a variety of psychological and biological factors, including sex. Females have been shown to perform better than males on a variety of declarative recall, recognition, and emotional memory tasks [17] [18], while males excel on visuospatial declarative memory tasks [18] [19]. However, very few studies have examined sex differences in non-declarative learning and more specifically in procedural learning. While Martin and colleagues [20] did not find any sex differences on a procedural learning task in individuals with and without HIV, they expressed that further investigation of sex differences was needed. A study by McDevitt and colleagues [21] demonstrated an interaction between sleep and sex, revealing that males showed greater learning on a non-declarative perceptual learning task after sleep, while females showed greater generalizability to new learning in new directions on the task.

It is important to understand the effect of sex on learning. Though there have been studies examining sex differences in declarative memory, there have been a lack of studies in non-declarative memory, and specifically in procedural learning. Furthermore, to our knowledge, there are no studies that have investigated these differences in procedural learning in Veterans. Thus, this preliminary study examined male and female Veterans with a range of co-morbidities (TBI, PTSD, and/or the presence of depression symptoms) to test the hypothesis that there would be sex differences in procedural cognitive and motor skill learning. Specifically, based on the declarative memory literature, we hypothesized that 
females would perform better on the cognitive skill-learning task while males would perform better on the motor skill-learning task.

\section{Methods}

\subsection{Participants}

Sixty-five (55 males, 10 females; 6 without TBI, 56 with mild TBI, and 3 with moderate TBI; 40 without PTSD ad 25 with PTSD; 36 without depression and 29 with depression) Veterans were seen at Stanford University and the Veterans Affairs Palo Alto Health Care System (VAPAHCS) (Table 1). Fifty-nine Veterans (51 males, and 8 females) completed the serial reaction time task (SRT: [22]) and fifty-six Veterans (48 males, 8 females) completed the weather prediction task (WPT; [23]). For the SRT, five males and 2 females were excluded from data analysis based on computer malfunction, not responding on more than $10 \%$ of the trials, having less than $75 \%$ accuracy on the task, or being an outlier. For the WPT, 8 males and 2 females were excluded from data analysis based on computer malfunction or not responding on more than $10 \%$ of the trials. All study procedures were approved by the Stanford University and VAPAHCS Institutional Review Board, and written informed consent was obtained from all participants. Potential participants were screened and excluded for reports of prior treatments for disorders affecting the central nervous system (e.g., seizure disorder, stroke), a diagnosis of dementia, current psychosis, history of alcohol or substance abuse/dependence within the past 5 years, learning disabilities, attention-deficit hyperactivity disorder, drug abuse less than six months prior to screening, and a penetrating TBI (as this can results in major anatomical and functional changes).

\subsection{SRT Design and Procedure}

In the SRT, participants were presented with a sequence of targets appearing in four positions and were asked to respond as quickly and accurately as possible to

Table 1. Demographics of the veterans.

\begin{tabular}{|c|c|c|c|c|c|}
\hline \multirow{2}{*}{ Variable } & \multicolumn{2}{|c|}{ Males $(n=55)$} & \multicolumn{2}{|c|}{ Females $(n=10)$} & \multirow{2}{*}{$\mathrm{P}$-value } \\
\hline & $\mathbf{M}$ & SD & $\mathbf{M}$ & SD & \\
\hline Age (years) & 41.58 & 13.81 & 41.30 & 11.14 & $p>0.05$ \\
\hline Education (years) ${ }^{*}$ & 14.51 & 1.89 & 16.40 & 1.90 & $p=0.005(\mathrm{~F}>\mathrm{M})$ \\
\hline Handedness (L/R/Both) & \multicolumn{2}{|c|}{$4 / 49 / 2$} & \multicolumn{2}{|c|}{$0 / 10 / 0$} & $p>0.05$ \\
\hline PTSD PCL-C IV (No/Yes) & \multicolumn{2}{|c|}{$34 / 21$} & \multicolumn{2}{|c|}{$6 / 4$} & $p>0.05$ \\
\hline $\begin{array}{c}\text { TBI severity } \\
\text { (none/mild/moderate) }\end{array}$ & \multicolumn{2}{|c|}{$5 / 47 / 3$} & \multicolumn{2}{|c|}{$1 / 9 / 0$} & $p>0.05$ \\
\hline $\begin{array}{l}\text { Depression symptoms } \\
\text { BDI-II (No/Yes) }\end{array}$ & \multicolumn{2}{|c|}{$30 / 25$} & \multicolumn{2}{|c|}{$6 / 4$} & $p>0.05$ \\
\hline
\end{tabular}

Posttraumatic stress disorder symptom severity civilian version (PTSD PCL-C); traumatic brain injury (TBI), Beck Depression Inventory (BDI). 
the target by pressing one of four spatially compatible buttons. On some sets of trials, unknown to participants, the locations occurred in a particular 12 item sequence. On other sets of trials, the locations were presented in a pseudorandom order. More details of the task are described elsewhere [24]. Each block included 24 consecutive sequence trials or 24 consecutive random trials. Whether sequence or random trials were presented first in a block was counterbalanced across participants. Over the course of learning, participants performed 824 trial blocks of the SRT task for a total of 192 trials. For data analysis, the difference in reaction time from the random and sequence trials (called benefit) was calculated for each block.

\subsection{WPT Design and Procedure}

In the WPT, participants were told to predict the weather (sun or rain) based on cues. On every trial between 1 and 3 cues (out of 4 possibilities) could appear, yielding 14 possible combinations. The cues were probabilistically related to the outcomes. The association of the different cues with different probabilities was randomized across participants. Over the course of learning, participants performed 5 - 10 trial blocks of the task for a total of 50 trials. More details of the task are described elsewhere [25].

\subsection{Clinical Measures and Evaluation}

Diagnosis of traumatic brain injury (TBI) was determined according to DoD/ DVA criteria assessing Alteration of Consciousness (AOC), Loss of Consciousness (LOC), and Post-traumatic amnesia (PTA) [26] ("VA/DoD Clinical Practice Guideline for Management of Concussion/Mild Traumatic Brain Injury”) [26]. PTSD status was established by using a criteria cutoff of 45 or more on the PCL-C. Depression symptom status was established by using a criteria cutoff of 14 or more on the BDI-II.

\subsection{Self-Report Questionnaires}

Participants completed self-report questionnaires for PTSD symptom severity (PCL-C IV; [27]), presence of depression symptoms (Beck Depression Inventory II (BDI-II); [28]), executive function (Behavior Rating Inventory of Executive Functioning (BRIEF; [29])), sleep (Pittsburgh Sleep Quality Index (PSQI; [30]), and functional outcome (Mayo Portland Adaptability Inventory (MPAI)-4; [31]).

\subsection{Statistical Analysis}

Data were analyzed using SPSS (V.21, SPSS, Chicago) and R

(http://www.r-project.org/). Differences between males and females on demographic and clinical data and self-report questionnaires were analyzed using an independent $t$-tests and chi-square tests where appropriate. Since age and education are known to affect learning [32], correlations with average performance 
were conducted to assess if there was a relationship between the variables. Significant associations were added to the model. A repeated measures linear mixed-effects model with sex (male vs. female) as the between subjects factor and block as the repeated measure was conducted to assess for sex differences in learning. Model building was implemented, using maximum likelihood, to determine the model that fit the data the best. Model fit with and without correlated demographic variables was assessed by examining statistical differences in $-2 \log$ likelihood values using a chi-squared test. Final model parameters were estimated with restricted maximum likelihood. Total learning slope (adapted from the CVLT-II [33], Appendix) was also calculated to analyze the total learning slope from the first to last block using an analysis of covariance (ANCOVA) with sex as the between subjects factor. Finally, based on the final model, partial correlations were run to assess the relationship between performance and the self-report questionnaires.

\section{Results}

\subsection{Demographics}

There were no differences in age, handedness, PTSD status, TBI severity, or depression symptom status between the groups, $p s>0.05$. There was a significant difference in education, $t(63)=-2.903, p=0.005$ for females $(\mathrm{M}=16.40, \mathrm{SD}=$ $1.90)$ to have greater number of years of education than males $(\mathrm{M}=14.51, \mathrm{SD}=$ 1.89) (Table 1).

\subsection{Correlations of Age and Education with the Tasks}

For the SRT, while education was not correlated with performance on the task, $r(59)=-0.162, p=0.221$, there was an association with age, $r(59)=-0.324, p=$ 0.012 , indicating that as reaction time for benefit improves, age decreases (Figure 1(a)); therefore, it was included as a covariate in linear mixed-effect and ANCOVA models. For the WPT, while age was not correlated to performance on the task, $r(56)=-0.107, p=0.430$, there was an association with education, $r(56)=0.301, p=0.024$, demonstrating that as performance (accuracy) improves, the number of years of education increases (Figure 1(b)); accordingly, it was included as a covariate in linear mixed-effect and ANCOVA models.

\subsection{Self-Report Questionnaires}

There were no significant group differences in any of the questionnaires, $p s>0.05$.

\subsection{SRT Performance}

Participant performance was evaluated with a repeated measures linear mixedeffects modelling with age as a covariate, sex as the between subjects factor, and block as the repeated measures. There was a significant main effect for sex, $\mathrm{F}(1$, 18) $=5.987, p=0.015$, where females performed better than males (Cohen's $\mathrm{d}=$ 0.93 ) (Figure 2(a)). There was also a main effect of age, $\mathrm{F}(1,18)=7.778, p=$ 


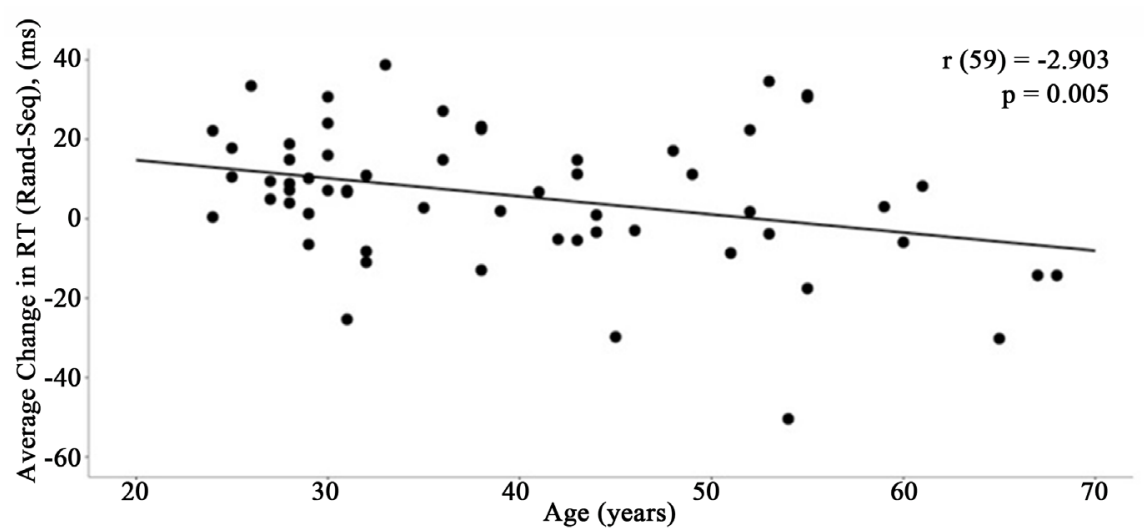

(a)

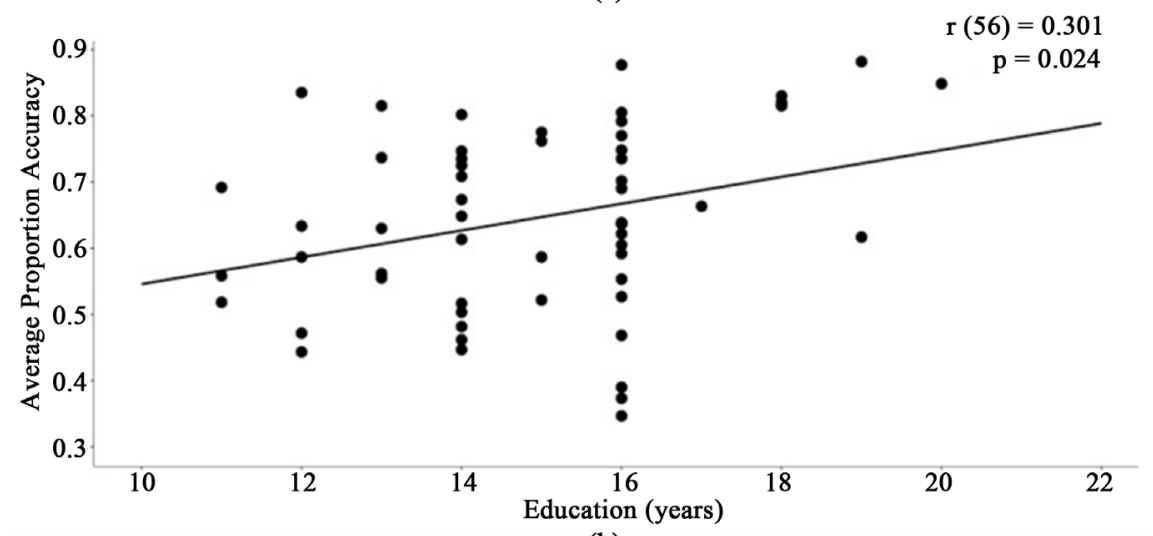

(b)

Figure 1. Correlations with performance. (a) Correlation of age and benefit (average change in reaction time [RT]) on the Serial Reaction Time (SRT) task and (b) Correlation of education and accuracy on the Weather Prediction Task (WPT).

0.006, where better performance was associated with younger age. However, there was no main effect for block, $\mathrm{F}(7,18)=0.384, p=0.910$, and an ANCOVA yielded no group differences on total learning slope, $\mathrm{F}(1,56)=0.874, p=0.354$ (Figure 2(b)), indicating males and females were equivalent on the rate of learning across trials. In addition, there were no significant associations between the self-report questionnaires and performance while controlling for age, $p s>$ 0.05 .

\subsection{WPT Performance}

Participant performance was evaluated with a repeated measures linear mixedeffects model with education as a covariate, sex as the between subjects factor and block as the repeated measures. There was a significant main effect for sex, $\mathrm{F}(1,12)=12.179, p=0.001$, where females performed better than males on the task (Cohen's $d=0.99$ ) (Figure $2(c)$ ). A main effect was observed for education, $\mathrm{F}(1,12)=4.413, p=0.037$, where Veterans with more years of education performed better on the task. A main effect was also yielded for block, $F(4,12)=$ 5.537, $p<0.001$, that showed greater accuracy over learning trials across participants. ANCOVA showed no difference between the groups on total learning 


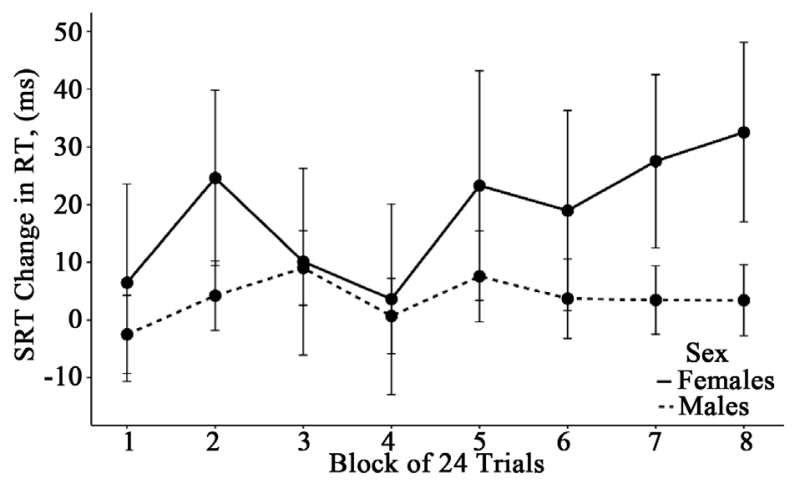

(a)

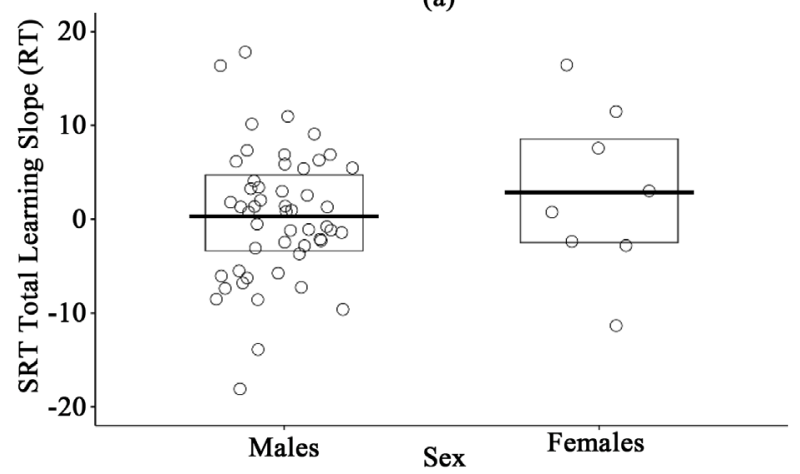

(b)
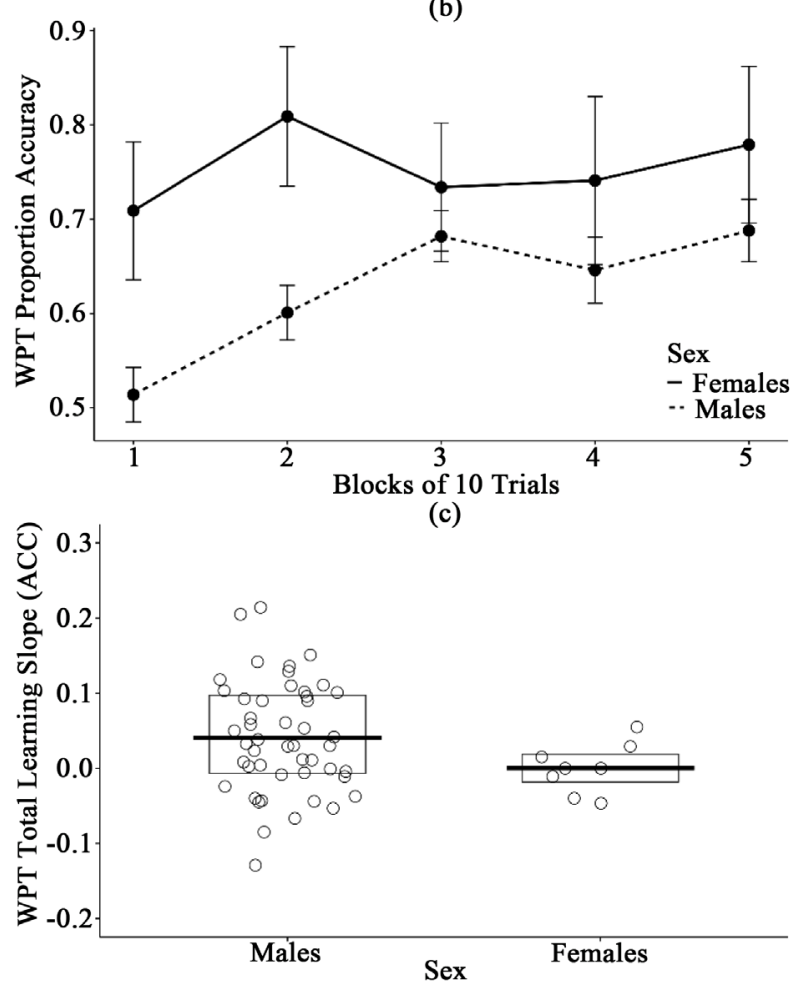

(d)

Figure 2. Serial Reaction Time (SRT) task and Weather Prediction Task (WPT) Performance. (a) SRT benefit of males and females across learning. Error bars represent the standard error of the mean; (b) SRT total learning slope for males and females; (c) WPT accuracy of males and females across learning. Error bars represent the standard error of the mean; and (d) WPT total learning slope for males and females. 
slope, $\mathrm{F}(1,53)=1.318, p=0.256$ (Figure $2(\mathrm{~d})$ ), indicating males and females were equivalent on the rate of learning across trials. In addition, there were no significant associations between the self-report questionnaires and performance while controlling for education, $p s>0.05$.

\section{Discussion}

This preliminary study sought to determine whether there were sex differences in motor and cognitive skill learning in Veterans with a range of co-morbid conditions. Our results indicated that females performed better than males on both tasks and the mean differences between groups demonstrated a large effect size. Although females had better overall performance on the procedural learning tasks compared to males, their rate of learning was equivalent. While sex differences in declarative memory have been documented [17] [18] [19], few studies have assessed for sex differences in procedural learning. One study that assessed for sex differences [20] did not find any sex differences on the WPT in individuals with and without HIV, though the authors did state that further studies were warranted.

Sex differences in skill learning in Veterans may have implications, especially for rehabilitation and deficit remediation. The higher risk of co-morbidities of TBI, PTSD, and depression in returning Veterans is a clinical concern, and better knowledge of the unique and collective attributes of these conditions could guide clinical best practices. Since Veterans with combat exposure are at greater risk for acquiring co-morbid conditions and the associated impairments in various domains [1] [2] [9], treating cognitive and motor deficits tailored specifically for females or males may improve the efficacy of certain interventions. For example, therapies designed to remediate cognitive impairment and improve functional outcome might show greater improvement by utilizing compensatory strategies for existing skills. A meta-analysis [34] of functional imaging studies of declarative memory in Alzheimer's disease patients demonstrated this phenomenon by showing that consistently greater activity in prefrontal regions among patients may represent compensatory increases in order to account for degeneration in temporal brain regions. Similarly, for female Veterans who have various impairments, deficits in other domains may be improved by incorporating elements of skill learning into an existing therapy.

To our knowledge, this is the first study to focus on sex differences in procedural skill learning in Veterans with a range of co-morbid conditions. However, there are substantial limitations to this preliminary study. Analysis of the results in the context of both tasks best demonstrates sex differences. While it is notable there is minimal evidence of learning in the SRT data, there is a trend in the literature that suggests this is an effective model to use despite not having a statistically significant result for learning [35]. Additionally, there has been some evidence that middle-aged adults (considered ages 30 - 50), the majority age group represented in our sample, do not demonstrate learning on the SRT [36]. We 
also cannot rule out the possibility that the lack of statistical significance is possibly due to low power from a low number of trials. Furthermore, the inclusion of this data is important to report as much can be learned from the looking at non-statistically significant findings as a base to inform future hypotheses. The small sample size of eight females in each task is prone to sampling bias; however, the percentage of females in this study is representative of the proportion of females seeking treatment at VA medical centers [37] [38]. Another important concern is the lack of information regarding the mechanism of injury and number of injuries for those Veterans in this sample with a history of TBI. While the majority have sustained mild injuries, whether the injuries are due to blast exposures or blunt force trauma is unknown. While the literature suggests there may be no differences on measures of neuropsychological functioning between blasts and blunt force trauma [39], less is known regarding skill learning in this population. Our Veteran population also demonstrated significant differences in education; however, we assessed if there was a relationship between education and skill learning in both tasks. There was a significant relationship between performance on the WPT and education. Thus, education was included in the model. Since there was no significant relationship between performance on the SRT and education, it was not included in the model. Since the impact of education was assessed, we do not believe that differences in education affected the sex differences seen in our tasks. Furthermore, normative data for common neuropsychological assessments often account for educational attainment when determining whether or not an individual's performance is impaired (see [40] as an example). As such, if education played a larger role in this relationship, we would have expected significant differences in the learning slopes between these groups across the tasks.

Future studies with neuropsychological and neuroimaging data also need to be conducted to acquire a better understanding of their neurocognitive profile, how structural and functional brain areas that support procedural learning relate to sex differences, and the relationship to TBI and other mental health disorders (i.e. PTSD and depression). A major limitation of the study is the number of female participants. Thus, future studies need to be conducted with a larger sample size in order to replicate the current findings. In addition, it would also be informative to examine a cohort with longitudinal data to determine if male Veterans catch up to the same level of performance of the female Veterans after extended training, as this could have important implications for rehabilitation of deficits. It is also important to note the Veteran population is medically complex. It is possible that other medical conditions and co-morbidities not assessed and accounted for in these analyses have reduced our statistical power in this study. Future studies focusing on assessing neuroanatomical changes associated with mild TBI, particularly DTI, can better tease apart the contributions of psychological, medical, and anatomical changes [41]. Finally, this study examined mean differences between the groups across learning as a first step. Utilization of 
classification approaches and data clustering techniques (such as K-means) to determine the accuracy of the measures employed in this study to predict sex (i.e., males and females) while considering common co-morbidities (TBI, PTSD, depression) may delineate sex differences in underlying neurobiological processes. Future studies would also be benefitted by including other common comorbidities in Veterans (ex. substance abuse) and medication, which may also impact procedural learning differently by sex. A better understanding of the relationship between these variables has the potential to influence the way that future rehabilitation activities are structured. Thus, it could bring us one step closer to generating personalized rehabilitation programs for medically complex individuals.

To the best of our knowledge, this is the first study to examine differences in procedural skill learning in Veterans with multiple co-morbidities. Although this data is preliminary, the pattern of results from the motor and cognitive skill leaning tasks suggests an effect of sex. Skill learning is an important requisite for rehabilitation of deficits, as skill learning is necessary to perform daily activities in new settings. Preserved skill learning in certain domains could be used to aid in interventions by helping to customize the tasks for optimal rehabilitation. For example, interventions designed to remediate cognitive or motor impairment might show greater improvement by utilizing compensatory strategies for existing skills. Improvement in specific "real life" activities of daily living, such as using a telephone or driving, may be expedited through a better understanding of these potential differences in learning. Ultimately, these results provide insight into skill learning in Veterans with a range of co-morbidities and provide support for further investigation of sex differences in procedural learning in larger samples.

\section{Acknowledgements}

We thank Stacy Moeder for her help in administration, and we thank the Veterans for the participation in research.

\section{References}

[1] Hoge, C.W., Castro, C.A., Messer, S.C., McGurk, D., Cotting, D.I. and Koffman, R.L. (2008) Combat Duty in Iraq and Afghanistan, Mental Health Problems and Barriers to Care. U.S. Army Medical Department Journal, 7-17.

[2] Seal, K.H., Bertenthal, D., Samuelson, K., Maguen, S., Kumar, S. and Vasterling, J.J. (2016) Association between Mild Traumatic Brain Injury and Mental Health Problems and Self-Reported Cognitive Dysfunction in Iraq and Afghanistan Veterans. Journal of Rehabilitation Research \& Development, 53, 185-198. https://doi.org/10.1682/JRRD.2014.12.0301

[3] Vanderploeg, R.D., Belanger, H.G. and Curtiss, G. (2009) Mild Traumatic Brain Injury and Posttraumatic Stress Disorder and Their Associations with Health Symptoms. Archives of Physical Medicine and Rehabilitation, 90, 1084-1093.

[4] Vanderploeg, R.D., Belanger, H.G., Horner, R.D., Spehar, A.M., Powell-Cope, G., Luther, S.L. and Scott, S.G. (2012) Health Outcomes Associated with Military Dep- 
loyment: Mild Traumatic Brain Injury, Blast, Trauma, and Combat Associations in the Florida National Guard. Archives of Physical Medicine and Rehabilitation, 93, 1887-1895.

[5] Hoge, C.W., McGurk, D., Thomas, J.L., Cox, A.L., Engel, C.C. and Castro, C.A. (2008) Mild Traumatic Brain Injury in U.S. Soldiers Returning from Iraq. The New England Journal of Medicine, 358, 453-463. https://doi.org/10.1056/NEJMoa072972

[6] Tanelian, T. and Jaycox, L.H. (2008) Invisible Wounds of War: Psychological and Cognitive Injuries, Their Consequences, and Services to Assist Recovery. RAND, Santa Monica.

[7] Thomas, J.L., Wilk, J.E., Riviere, L.A., McGurk, D., Castro, C.A. and Hoge, C.W. (2010) Prevalence of Mental Health Problems and Functional Impairment among Active Component and National Guard Soldiers 3 and 12 Months Following Combat in Iraq. Archives of General Psychiatry, 67, 614-623. https://doi.org/10.1001/archgenpsychiatry.2010.54

[8] Belanger, H.G., Curtiss, G., Demery, J.A., Lebowitz, B.K. and Vanderploeg, R.D. (2005) Factors Moderating Neuropsychological Outcomes Following Mild Traumatic Brain Injury: A Meta-Analysis. Journal of the International Neuropsychological Society, 11, 215-227. https://doi.org/10.1017/S1355617705050277

[9] Combs, H.L., Berry, D.T., Pape, T., Babcock-Parziale, J., Smith, B., Schleenbaker, R., Shandera-Ochsner, A., Harp, J.P. and High, W.M. (2015) The Effects of Mild Traumatic Brain Injury, Post-Traumatic Stress Disorder, and Combined Mild Traumatic Brain Injury/Post-Traumatic Stress Disorder on Returning Veterans. Journal of Neurotrauma, 32, 956-966. https://doi.org/10.1089/neu.2014.3585

[10] Johnsen, G.E. and Asbjornsen, A.E. (2008) Consistent Impaired Verbal Memory in PTSD: A Meta-Analysis. Journal of Affective Disorders, 111, 74-82.

[11] Cohen, N.J. and Squire, L.R. (1980) Preserved Learning and Retention of PatternAnalyzing Skill in Amnesia: Dissociation of Knowing How and Knowing That. Science, 210, 207-210. https://doi.org/10.1126/science.7414331

[12] Squire, L.R. and Zola, S.M. (1996) Structure and Function of Declarative and Nondeclarative Memory Systems. Proceedings of the National Academy of Sciences of the United States, 93, 13515-13522. https://doi.org/10.1073/pnas.93.24.13515

[13] Nadeau, S.E. (2002) A Paradigm Shift in Neurorehabilitation. The Lancet Neurology, 1, 126-130.

[14] Bahar-Fuchs, A., Clare, L. and Woods, B. (2013) Cognitive Training and Cognitive Rehabilitation for Persons with Mild to Moderate Dementia of the Alzheimer's or Vascular Type: A Review. Alzheimer's Research \& Therapy, 5, 35. https://doi.org/10.1186/alzrt189

[15] Diez-Cirarda, M., Ojeda, N., Pena, J., Cabrera-Zubizarreta, A., Lucas-Jimenez, O., Gomez-Esteban, J.C., Gomez-Beldarrain, M.A. and Ibarretxe-Bilbao, N. (2016) Increased Brain Connectivity and Activation after Cognitive Rehabilitation in Parkinson's Disease: A Randomized Controlled Trial. Brain Imaging and Behavior, 1-12. https://doi.org/10.1007/s11682-016-9639-x

[16] Wykes, T. and Spaulding, W.D. (2011) Thinking about the Future Cognitive Remediation Therapy-What Works and Could We Do Better? Schizophrenia Bulletin, 37, S80-S90. https://doi.org/10.1093/schbul/sbr064

[17] Canli, T., Desmond, J.E., Zhao, Z. and Gabrieli, J.D. (2002) Sex Differences in the Neural Basis of Emotional Memories. Proceedings of the National Academy of Sciences of the United States, 99, 10789-10794.

https://doi.org/10.1073/pnas.162356599 
[18] Lewin, C., Wolgers, G. and Herlitz, A. (2001) Sex Differences Favoring Women in Verbal but not in Visuospatial Episodic Memory. Neuropsychology, 15, 165-173. https://doi.org/10.1037/0894-4105.15.2.165

[19] Herlitz, A., Airaksinen, E. and Nordstrom, E. (1999) Sex Differences in Episodic Memory: The Impact of Verbal and Visuospatial Ability. Neuropsychology, 13, 590 597. https://doi.org/10.1037/0894-4105.13.4.590

[20] Martin, E., Gonzalez, R., Vassileva, J. and Maki, P. (2011) HIV+ Men and Women Show Different Performance Patterns on Procedural Learning Tasks. Journal of Clinical and Experimental Neuropsychology, 33, 112-120. https://doi.org/10.1080/13803395.2010.493150

[21] McDevitt, E.A., Rokem, A., Silver, M.A. and Mednick, S.C. (2014) Sex Differences in Sleep-Dependent Perceptual Learning. Vision Research, 99, 172-179.

[22] Nissen, M.J. and Bullemer, P. (1987) Attentional Requirements of Learning: Evidence from Performance Measures. Cognitive Psychology, 19, 1-32.

[23] Knowlton, B.J., Squire, L.R. and Gluck, M.A. (1994) Probabilistic Classification Learning in Amnesia. Learning \& Memory, 1, 106-120.

[24] Foerde, K., Poldrack, R.A., Khan, B.J., Sabb, F.W., Bookheimer, S.Y., Bilder, R.M., Guthrie, D., Granholm, E., Nuechterlein, K.H., Marder, S.R. and Asarnow, R.F. (2008) Selective Corticostriatal Dysfunction in Schizophrenia: Examination of Motor and Cognitive Skill Learning. Neuropsychology, 22, 100-109. https://doi.org/10.1037/0894-4105.22.1.100

[25] Wagshal, D., Knowlton, B.J., Cohen, J.R., Poldrack, R.A., Bookheimer, S.Y., Bilder, R.M., Fernandez, V.G. and Asarnow, R.F. (2012) Deficits in Probabilistic Classification Learning and Liability for Schizophrenia. Psychiatry Research, 200, 167-172.

[26] Management of Concussion/mTBI Working Group (2009) VA/DoD Clinical Practice Guideline for Management of Concussion/Mild Traumatic Brain Injury. Journal of Rehabilitation Research \& Development, 46, CP1-68.

[27] Weathers, F.W., Litz, B.T., Herman, D.S., Huska, J.A. and Keane, T.M. (1993) The PTSD Checklist (PCL): Reliability, Validity, and Diagnostic Utility. Annual Convention of the International Society for Traumatic Stress Studies, San Antonio.

[28] Beck, A., Steer, R. and Brown, G. (1996) Manual for the Beck Depression Inventory-II. Psychological Corporation, San Antonio.

[29] Gioia, G.A., Isquith, P.K., Guy, S.C. and Kenworthy, L. (2000) BRIEF: Behavior Rating Inventory of Executive Function. Psychological Assessment Resources, Lutz.

[30] Buysse, D.J., Reynolds, C.F., Monk, T.H., Berman, S.R. and Kupfer, D.J. (1989) The Pittsburgh Sleep Quality Index: A New Instrument for Psychiatric Practice and Research. Psychiatry Research, 28, 193-213.

[31] Malec, J.F. and Lezak, M.D. (2008) Manual for the Mayo-Portland Adaptability Inventory.

[32] Heaton, R.K., Miller, S.W., Taylor, M.J. and Grant, I. (2004) Revised Comprehensive Norms for an Expanded Halstead-Reitan Battery: Demographically Adjusted Neuropsychological Norms for African American and Caucasian Adults. Lutz.

[33] Delis, D.C., Kramer, J.H., Kaplan, E. and Ober, B.A. (2000) California Verbal Learning Test. San Antonio.

[34] Schwindt, G.C. and Black, S.E. (2009) Functional Imaging Studies of Episodic Memory in Alzheimer's Disease: A Quantitative Meta-Analysis. Neuroimage, 45, 181-190. 
[35] Bloch, A., Tamir, D., Vakil, E. and Zeilig, G. (2016) Specific Deficit in Implicit Motor Sequence Learning following Spinal Cord Injury. PLOS ONE, 11, e0158396. https://doi.org/10.1371/journal.pone.0158396

[36] Meissner, S.N., Keitel, A., Sudmeyer, M. and Pollok, B. (2016) Implicit Motor Sequence Learning and Working Memory Performance Changes across the Adult Life Span. Frontiers in Aging Neuroscience, 8, 89. https://doi.org/10.3389/fnagi.2016.00089

[37] Goldzweig, C.L., Balekian, T.M., Rolon, C., Yano, E.M. and Shekelle, P.G. (2006) The State of Women Veterans' Health Research. Results of a Systematic Literature Review. Journal of General Internal Medicine, 21, S82-S92. https://doi.org/10.1111/j.1525-1497.2006.00380.x

[38] Kang, H. (2008) OEF/OIF Utilization Data, FY 2008 2nd Quarter. Department of Veterans Affairs, OPHEH, Washington DC.

[39] Belanger, H.G., Kretzmer, T., Yoash-Gantz, R., Pickett, T. and Tupler, L.A. (2009) Cognitive Sequelae of Blast-Related versus Other Mechanisms of Brain Trauma. Journal of the International Neuropsychological Society, 15, 1-8. https://doi.org/10.1017/S1355617708090036

[40] Shenton, M.E., Hamoda, H.M., Schneiderman, J.S., Bouix, S., Pasternak, O., Rathi, Y., Vu, M.A., Purohit, M.P., Helmer, K., Koerte, I., Lin, A.P., Westin, C.F., Kikinis, R., Kubicki, M., Stern, R.A. and Zafonte, R.. (2012) A Review of Magnetic Resonance Imaging and Diffusion Tensor Imaging Findings in Mild Traumatic Brain Injury. Brain Imaging and Behavior, 6, 137-192. https://doi.org/10.1007/s11682-012-9156-5

[41] Mitrushina, M., Boone, K.B., Razani, J. and D’Elia, L.F. (2005) Handbook of Normative Data for Neuropsychological Assessment. Oxford University Press, Oxford.

Submit or recommend next manuscript to SCIRP and we will provide best service for you:

Accepting pre-submission inquiries through Email, Facebook, LinkedIn, Twitter, etc. A wide selection of journals (inclusive of 9 subjects, more than 200 journals)

Providing 24-hour high-quality service

User-friendly online submission system

Fair and swift peer-review system

Efficient typesetting and proofreading procedure

Display of the result of downloads and visits, as well as the number of cited articles

Maximum dissemination of your research work

Submit your manuscript at: http://papersubmission.scirp.org/

Or contact jbbs@scirp.org 